\title{
Optical band gaps and composition dependence of hafnium-aluminate thin films grown by atomic layer chemical vapor deposition
}

N. V. Nguyen, S. Sayan, I. Levin, J. R. Ehrstein, I. J. R. Baumvol, C. Driemeier, C. Krug, L. Wielunski, P. Y. Hung, and Alain Diebold

Citation: Journal of Vacuum Science \& Technology A 23, 1706 (2005); doi: 10.1116/1.2091096

View online: https://doi.org/10.1116/1.2091096

View Table of Contents: https://avs.scitation.org/toc/jva/23/6

Published by the American Vacuum Society

\section{ARTICLES YOU MAY BE INTERESTED IN}

Energy gap and band alignment for $\left(\mathrm{HfO}_{2}\right)_{x}\left(\mathrm{Al}_{2} \mathrm{O}_{3}\right)_{1-\mathrm{x}}$ on (100) Si

Applied Physics Letters 81, 376 (2002); https://doi.org/10.1063/1.1492024

Crystal structure and band gap determination of $\mathrm{HfO} \mathrm{O}_{2}$ thin films Journal of Applied Physics 101, 054101 (2007); https://doi.org/10.1063/1.2697551

Spectroscopic ellipsometry characterization of high-k dielectric $\mathrm{HfO}_{2}$ thin films and the high-temperature annealing effects on their optical properties

Applied Physics Letters 80, 1249 (2002); https://doi.org/10.1063/1.1448384

High-k gate dielectrics: Current status and materials properties considerations

Journal of Applied Physics 89, 5243 (2001); https://doi.org/10.1063/1.1361065

Parameterization of the optical functions of amorphous materials in the interband region Applied Physics Letters 69, 371 (1996); https://doi.org/10.1063/1.118064

Sub-bandgap defect states in polycrystalline hafnium oxide and their suppression by admixture of silicon Applied Physics Letters 87, 192903 (2005); https://doi.org/10.1063/1.2126136

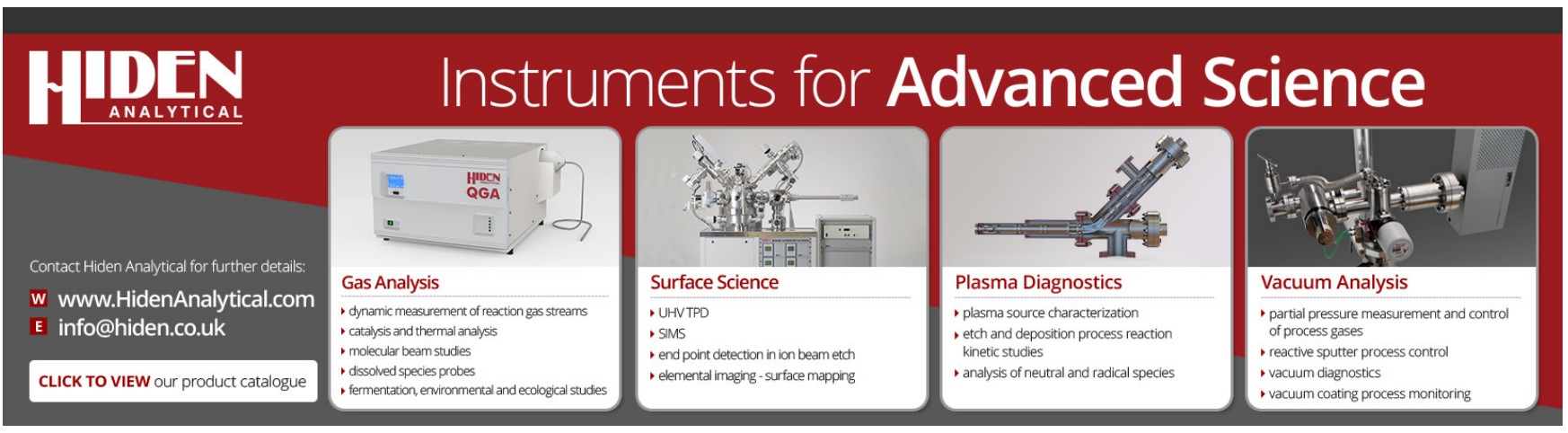




\title{
Optical band gaps and composition dependence of hafnium-aluminate thin films grown by atomic layer chemical vapor deposition
}

\author{
N. V. Nguyen ${ }^{\text {a) }}$ \\ Semiconductor Electronics Division, National Institute of Standards and Technology, Gaithersburg, \\ Maryland 20899 \\ S. Sayan \\ Department of Chemistry, Rutgers University, Piscataway, New Jersey 08854 \\ I. Levin \\ Ceramics Division, National Institute of Standards and Technology, Gaithersburg, Maryland 20899 \\ J. R. Ehrstein \\ Semiconductor Electronics Division, National Institute of Standards and Technology, Gaithersburg, \\ Maryland 20899 \\ I. J. R. Baumvol and C. Driemeier \\ Instituto de Fisica, UFRGS, 91509-900 Porto Alegre, RS, Brazil \\ C. Krug \\ Department of Physics, North Carolina State University, Raleigh, North Carolina 27695 \\ L. Wielunski \\ Department of Physics and Astronomy, Rutgers University, Piscataway, New Jersey 08854 \\ P. Y. Hung and Alain Diebold \\ International Sematech, Austin, Texas 78741
}

(Received 30 September 2004; accepted 29 August 2005; published 25 October 2005)

\begin{abstract}
We report the optical properties of unannealed hafnium-aluminate (HfAlO) films grown by atomic layer chemical vapor deposition (ALCVD) and correlate them with the aluminum contents in the films. Vacuum ultraviolet spectroscopic ellipsometry (VUV-SE), high-resolution transmission electron microscopy (HRTEM), channeling Rutherford backscattering spectrometry (RBS), and resonant nuclear reaction analysis (NRA) were employed to characterize these films. In the analyses of ellipsometry data, a double Tauc-Lorentz dispersion produces a best fit to the experimental VUV-SE data. As a result, the determined complex pseudodielectric $\langle\varepsilon\rangle$ functions of the films clearly exhibit a dependency on the aluminum densities measured by RBS and NRA. We show that the optical fundamental band gap $E_{g}$ shifts from $5.56 \pm 0.05 \mathrm{eV}$ for $\mathrm{HfO}_{2}$ to $5.92 \pm 0.05 \mathrm{eV}$ for $\mathrm{HfAlO}$. The latter was grown by using an equal number of pulses of $\mathrm{H}_{2} \mathrm{O} / \mathrm{HfCl}_{4}$ and $\mathrm{H}_{2} \mathrm{O} / \mathrm{TMA}$ (trimethylaluminum) precursors in each deposition cycle for $\mathrm{HfO}_{2}$ and $\mathrm{Al}_{2} \mathrm{O}_{3}$, respectively. The shift of $E_{g}$ to higher photon energies with increasing aluminum content indicates that intermixing of $\mathrm{HfO}_{2}$ and $\mathrm{Al}_{2} \mathrm{O}_{3}$ occurred during the ALCVD growth process. We found that $E_{g}$ varies linearly with the mole fraction $x$ of $\mathrm{Al}_{2} \mathrm{O}_{3}$ in the alloy $\left(\mathrm{HfO}_{2}\right)_{x}\left(\mathrm{Al}_{2} \mathrm{O}_{3}\right)_{1-x}$, but has a parabolic dependency with the aluminum density. We also observed a consistent decrease in the magnitudes of the real $\left\langle\varepsilon_{1}\right\rangle$ and imaginary $\left\langle\varepsilon_{2}\right\rangle$ part of $\langle\varepsilon\rangle$ of $\mathrm{HfAlO}$ films with respect to those of $\mathrm{HfO}_{2}$ as the Al density increased. The absence of the $\approx 5.7 \mathrm{eV}$ peak in the $\langle\varepsilon\rangle$ spectrum, which was previously reported for polycrystalline $\mathrm{HfO}_{2}$ films, indicates that these films are amorphous as confirmed by their HRTEM images. (C) 2005 American Vacuum Society. [DOI: 10.1116/1.2091096]
\end{abstract}

\section{INTRODUCTION}

High- $k$ dielectric thin films have been the subject of a strong focus in the past years within the integrated circuit (IC) industry and academic research communities as a potential replacement for the traditional $\mathrm{SiO}_{2}$ gate dielectric in complementary metal-oxide-semiconductor devices. ${ }^{1}$ According to the International Technology Roadmap for Semiconductors, $\mathrm{SiO}_{2}$ gate thicknesses of less than $2 \mathrm{~nm}$ will be required in sub-0.1 $\mu \mathrm{m}$ MOS devices. ${ }^{2}$ In this range of thick-

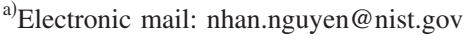

ness, the use of the $\mathrm{SiO}_{2}$ and $\mathrm{SiO}_{x} \mathrm{~N}_{y}$ layers as dielectric gates will not be acceptable for many applications due to the high tunneling currents. By exploiting the higher permittivity of high- $k$ dielectrics, one can grow a physically much thicker gate dielectric layer while still having thinner $\mathrm{SiO}_{2}$ equivalent oxide thickness $(\mathrm{EOT})^{3}$ and, thereby, significantly reduce the tunneling leakage currents. Various high- $k$ materials have been examined including $\mathrm{Ta}_{2} \mathrm{O}_{5}, \mathrm{TiO}_{2}, \mathrm{Al}_{2} \mathrm{O}_{3}, \mathrm{ZrO}_{2}$, $\mathrm{HfO}_{2}, \mathrm{Zr}$-silicates, $\mathrm{Zr}$-aluminates, and $\mathrm{Hf}$-aluminates. ${ }^{4}$ Among these possible candidates, $\mathrm{HfO}_{2}$ has been considered as a likely replacement for $\mathrm{SiO}_{2}$ due to its high permittivity 
TABLE I. Summary of the experimental results obtained from the VUV-SE, RBS, and NRA measurements. Targeted film composition is denoted by $\boldsymbol{n}[\boldsymbol{p}(\mathrm{HO}): \boldsymbol{q}(\mathrm{AO})]$ where $\boldsymbol{p}$ is number of $\mathrm{H}_{2} \mathrm{O} /$ TMA cycles followed by $\boldsymbol{q}$ cycles of $\mathrm{H}_{2} \mathrm{O} / \mathrm{HfCl}_{4}$; and this sequence is repeated $n$ times. The targeted film composition $\boldsymbol{q}$ : $\boldsymbol{p}$ ratio controls the composition $x$ of the $\left(\mathrm{HfO}_{2}\right)_{x}\left(\mathrm{Al}_{2} \mathrm{O}_{3}\right)_{1-x}$ alloy (see text of Fig. 6). The film thicknesses and optical band gaps $\left(E_{g}\right)$ are obtained from modeling the spectroscopy ellipsometry data. The aluminum concentrations $\left(Q_{\mathrm{Al}}\right)$ in units of $10^{15}$ atoms $/ \mathrm{cm}^{2}$ are determined by NRA whereas those of hafnium $\left(Q_{\mathrm{Hf}}\right)$ and oxygen $\left(Q_{\mathrm{O}}\right)$ determined by RBS. The estimated precision is $\pm 10 \%$ for $\mathrm{Al}$ concentrations unless otherwise stated. The estimated concentration precisions are $\pm 3 \%, \pm 10 \%$, and $\pm 30 \%$ for $\mathrm{Hf}, \mathrm{O}$, and $\mathrm{Cl}$, respectively.

\begin{tabular}{cccccccc}
\hline \hline Samples & $\begin{array}{c}\text { Composition } \\
\boldsymbol{n}[\boldsymbol{p}(\mathrm{HO}): \boldsymbol{q}(\mathrm{AO})]\end{array}$ & $\begin{array}{c}\text { Thickness } \\
(\AA)\end{array}$ & $E_{g} \pm 0.05(\mathrm{eV})$ & $Q_{\mathrm{Hf}}$ & $Q_{\mathrm{Al}}$ & $Q_{\mathrm{O}}$ & $Q_{\mathrm{Cl}}$ \\
\hline S2 & $30[1(\mathrm{HO}): 1(\mathrm{AO})]$ & 51.5 & 5.97 & 5.3 & 10.2 & 25.5 & 0.2 \\
S5 & $40[1(\mathrm{HO}): 1(\mathrm{AO})]$ & 64.5 & 5.88 & 6.5 & 13.7 & 29.6 & 0.3 \\
S7 & $50[1(\mathrm{HO}): 1(\mathrm{AO})]$ & 77.1 & 5.91 & 9.0 & 19.5 & 43.5 & 0.4 \\
S9 & $15[5(\mathrm{HO}): 1(\mathrm{AO})]$ & 60.7 & 5.68 & 12.9 & 4.3 & 38.0 & 0.5 \\
S12 & $20[5(\mathrm{HO}): 1(\mathrm{AO})]$ & 78.9 & 5.72 & 15.9 & 5.8 & 43.1 & 0.5 \\
S14 & $25[5(\mathrm{HO}): 1(\mathrm{AO})]$ & 93.2 & 5.76 & 18.9 & 7.7 & 46.7 & 0.5 \\
S16 & $74[5(\mathrm{HO}): 0(\mathrm{AO})]$ & 48.1 & 5.58 & 11.1 & - & 25.0 & 0.3 \\
S19 & $92[5(\mathrm{HO}): 0(\mathrm{AO})]$ & 56.3 & 5.54 & 13.7 & - & 28.8 & 0.3 \\
S21 & {$[37(\mathrm{HO}): 5(\mathrm{AO}): 37(\mathrm{HO})]^{\mathrm{a}}$} & 52.2 & 5.62 & 10.8 & $2.0 \pm 0.4$ & 29.1 & 0.3 \\
S24 & {$[46(\mathrm{HO}): 5(\mathrm{AO}): 46(\mathrm{HO})]^{\mathrm{a}}$} & 61.1 & 5.58 & 13.4 & $2.2 \pm 0.4$ & 31.9 & 0.3 \\
\hline \hline
\end{tabular}

${ }^{\mathrm{a}}$ The growth sequence consisted of 37 or $46 \mathrm{H}_{2} \mathrm{O}$ / TMA cycles followed by 5 cycles of $\mathrm{H}_{2} \mathrm{O} / \mathrm{HfCl}_{4}$ and finished with 37 or $46 \mathrm{H}_{2} \mathrm{O} / \mathrm{TMA}$ cycles.

and thermodynamic stability with silicon. ${ }^{5}$ However, in the subsequent fabrication steps, the stability of $\mathrm{HfO}_{2}$ against crystallization improves significantly upon alloying with $\mathrm{Al}_{2} \mathrm{O}_{3}$ to form Hf-aluminates. ${ }^{6-8}$

This article shows that vacuum ultraviolet spectroscopic ellipsometry (VUV-SE) is able to correlate the optical properties and optical bandgap $\left(E_{g}\right)$ of Hf-aluminate films with their aluminum composition. Due to the relatively large band gaps $(3.5-7 \mathrm{eV})$ of most high- $k$ materials of technological importance, VUV-SE with a spectral range extended to $\approx 9.0 \mathrm{eV}$ was found to be the most suitable technique to ascertain the optical properties near and above the fundamental band gap. ${ }^{9-13}$ In this spectral range, $E_{g}$ can be readily determined. We show that the $E_{g}$ value deduced experimentally varied with the amount of the $\mathrm{Al}_{2} \mathrm{O}_{3}$ used to grow $\mathrm{Hf}$-aluminate films. Complementary experiments including high-resolution electron transmission microscopy (HRTEM), channeling Rutherford backscattering spectrometry (RBS), and resonant nuclear reaction analysis (NRA) were also performed on the same set of films to evaluate the interface layer, film thickness, and atomic concentrations of hafnium, oxygen, and aluminum. We observe that the determined complex pseudodielectric functions $\left(\langle\varepsilon\rangle=\left\langle\varepsilon_{1}\right\rangle+i\left\langle\varepsilon_{2}\right\rangle\right)$ of the $\mathrm{HfO}_{2}$ and HfAlO films exhibit a shift of the fundamental band gap $E_{g}$ from $5.56 \mathrm{eV}$ for $\mathrm{HfO}_{2}$ to $5.92 \mathrm{eV}$ for $\mathrm{HfAlO}$ where the latter was grown with an equal $(1: 1)$ ratio of $\mathrm{HfO}_{2}$ and $\mathrm{Al}_{2} \mathrm{O}_{3}$. We also observe a consistent decrease in the magnitudes of $\left\langle\varepsilon_{1}\right\rangle$ and $\left\langle\varepsilon_{2}\right\rangle$ of HfAlO films with respect to that of $\mathrm{HfO}_{2}$ as the $\mathrm{Al}$ density increased. Further, the broad feature above the band gap in the $\langle\varepsilon\rangle$ spectrum indicates the amorphous structure of the as-grown films. HRTEM images confirmed the amorphous nature of the films. With respect to the oxygen density, RBS and NRA results indicate an apparently slight oxygen deficiency.

\section{EXPERIMENT AND DATA ANALYSIS}

A series of ten wafers of $\mathrm{HfO}_{2}$ and $\mathrm{Hf}$-aluminate films of different thicknesses and various content of $\mathrm{Al}$ was employed in this study. These films were deposited by atomic layer chemical vapor deposition (ALCVD). In ALCVD, precursors are introduced alternately to the silicon substrate with inert gas purged between each introduction. The two precursors pulsed in each deposition cycle consist of $\mathrm{H}_{2} \mathrm{O} / \mathrm{HfCl}_{4}$ (hafnium tetrachloride) for $\mathrm{HfO}_{2}$ deposition and $\mathrm{H}_{2} \mathrm{O} / \mathrm{TMA}$ (trimethylaluminum) for $\mathrm{Al}_{2} \mathrm{O}_{3}$ deposition. The growth sequence, denoted by $n^{*}(p \mathrm{AO}: q \mathrm{HO})$, is listed in Table $\mathrm{I}$, where $p$ is number of $\mathrm{H}_{2} \mathrm{O} / \mathrm{TMA}$ cycles followed by $q$ cycles of $\mathrm{H}_{2} \mathrm{O} / \mathrm{HfC}_{14}$, and then, these two sets of cycles were repeated $n$ times. Therefore, the ratio of $p$ and $q$ controls the composition and the total number of cycles $n$ determines the film thickness. The reactive precursor absorbs chemically on the wafer surface and undergoes a self-limiting reaction, and consequently a monolayer film growth can be achieved. ${ }^{14}$ As a result, a uniform and conformal growth is attainable, and the film thickness can be easily controlled by setting the total number of growth cycles. In our experiment, after the standard $\mathrm{SC} 1 / \mathrm{SC} 2$ wet chemical cleaning of silicon substrates, a thin layer of rapid thermal $\mathrm{SiO}_{2}(\approx 1.2 \mathrm{~nm})$ was grown to be used as active surface sites for the subsequent film growth. Such a thin $\mathrm{SiO}_{2}$ layer has been shown to be necessary to facilitate a uniform film growth, to ensure a linear growth rate, and also to achieve a well-controlled and well-behaved growth of films of amorphous structure at low temperatures. ${ }^{15}$ Various targeted film compositions were deposited as shown in Table I.

All spectroscopic ellipsometry measurements were performed on a vacuum ultraviolet spectroscopic ellipsometer (SE). The measured spectral range was scanned from 1.5 to 
$9.0 \mathrm{eV}$, in steps of $0.01 \mathrm{eV}$ and the angle of incidence was set at $75^{\circ}$. To determine the thickness and the pseudodielectric functions of each film, we utilized a model consisting of the crystalline silicon $(c-\mathrm{Si})$ substrate, the interfacial layer of $\mathrm{SiO}_{2}$, and the $\mathrm{HfO}_{2}$ or $\mathrm{Hf}$-aluminate film. The incorporation of the $\mathrm{SiO}_{2}$ interfacial layer of $11 \AA$ in the model was justified by the HRTEM images (Fig. 1) measured for samples S5 and $\mathrm{S} 9$ and the same $\mathrm{SiO}_{2}$ thickness is assumed for all samples. The uncertainty of the $\mathrm{SiO}_{2}$ thickness is about $1.5 \AA$ which was found to have negligible effects on the SE results, specifically on the determination of the optical band gaps of the films. The dielectric function of the Si substrate extended to $8.3 \mathrm{eV}$, and the refractive indices of $\mathrm{SiO}_{2}$ were obtained from the literature. ${ }^{16}$ To fit the experimental ellipsometric data, $\Delta$ and $\Psi$, the dielectric function of the films is assumed to follow a dielectric dispersive relation. The most used dispersion equation for amorphous materials is the TaucLorentz (TL) developed by Jellison and Modine. ${ }^{17}$ In this dispersion, the real part $\left(\varepsilon_{1}\right)$ of the complex dielectric function $(\varepsilon)$ is obtained by multiplying the imaginary part $\left(\varepsilon_{2}\right)$ expression of the Lorentz oscillator and the Tauc joint density of states. $\varepsilon_{1}$ was then analytically deduced from $\varepsilon_{2}$ by use of the classical self-consistency Kramer-Kronig integration:

$$
\begin{aligned}
& \varepsilon_{2}(E)=\left\{\begin{array}{l}
\frac{A E_{0} C\left(E-E_{g}\right)^{2}}{\left(E^{2}-E_{0}^{2}\right)^{2}+C^{2} E^{2}} \frac{1}{E} \quad\left(E>E_{g}\right) \\
0 \quad\left(E<E_{g}\right),
\end{array}\right. \\
& \varepsilon_{1}(E)=\varepsilon_{\infty}+\frac{2}{\pi} P \int_{0}^{\infty} \frac{\xi \varepsilon_{2}(\xi)}{\xi^{2}-E^{2}} d \xi,
\end{aligned}
$$

where $A, E_{g}, E_{0}$, and $C$ are positive constant fitting parameters in units of energy, and, $\varepsilon_{\infty}$ is a dimensionless fitting constant. All the TL fitting parameters and film thicknesses were deduced from the biased least squares.

The phase contrast imaging and electron energy loss spectroscopy (EELS) were conducted in a JEOL-3010-UHR (300 kV) HRTEM equipped with a Gatan imaging filter (GIF) and a slow-scan CCD camera. The EELS experiments were conducted by rotating the HRTEM image so that the interfaces were set parallel to the energy-dispersion direction of the GIF. The analyzed area was selected by the GIF entrance aperture. The EELS spectra containing low-loss regions and characteristic $\mathrm{Hf} N_{4,5}, \mathrm{SiAl} L_{2,3}$, Si $L_{2,3}$, and $\mathrm{O} K$ edges were recorded with an energy dispersion of $0.1 \mathrm{eV} / \mathrm{ch}$. Under the chosen experimental conditions, spatial resolutions of about $1 \mathrm{~nm}$ were obtained. HRTEM images of samples S5 and S9 are shown in Fig. 1. According to the EELS analysis, the upper dark layers in both images correspond to amorphous Hf-aluminate whereas the interfacial layer about $1.1 \mathrm{~nm}$ thick was identified with silicon oxide.

RBS was performed in channeling configuration to quantify $\mathrm{Hf}, \mathrm{O}$, and $\mathrm{Cl}$. The $\langle 001\rangle$ axis of $\mathrm{Si}(100)$ substrates was aligned to the direction of incidence of a $\mathrm{He}^{+}$primary beam at $1 \mathrm{MeV}$. Scattered particles were detected at $110^{\circ}$ with respect to the direction of ion beam incidence. Elemental
$1 \mathrm{AO}: 5 \mathrm{HO}$

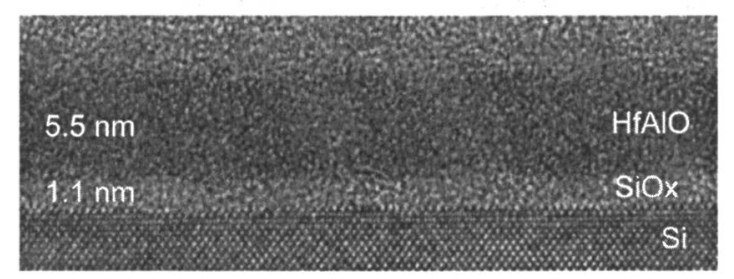

$1 \mathrm{AO}: 1 \mathrm{HO}$

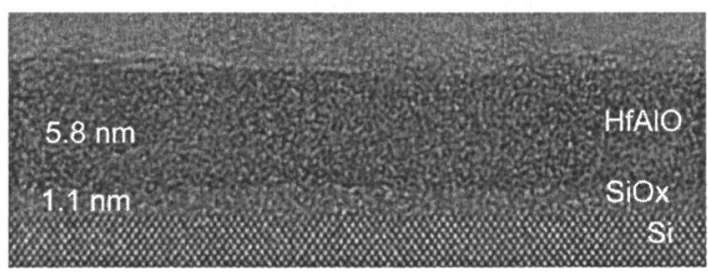

FIG. 1. HRTEM images for samples S5 and S9 used to determine the interface $\mathrm{SiO}_{2}$ layer of thickness $11 \AA$ in the SE data analysis.

amounts (areal densities) $Q_{i}$ were calculated from the area of the RBS signals, referenced to a Harwell series II $\mathrm{Si}(\mathrm{Bi})$ standard and corrected for the change in cross section. The estimated precision in these measurements is $\pm 3 \%$ for $\mathrm{Hf}$, $\pm 10 \%$ for $\mathrm{O}$, and $\pm 30 \%$ for $\mathrm{Cl}$. No carbon was detected, indicating an areal density below $10^{16} \mathrm{~cm}^{-2}$.

NRA was performed to quantify and profile aluminum. Quantification was accomplished by using the narrow (FWHM $<100 \mathrm{eV}$ ) resonance at $992.0 \mathrm{keV}$ in the crosssection curve of the ${ }^{27} \mathrm{Al}(p, \gamma){ }^{28} \mathrm{Si}$ reaction. Proton incidence was normal to the sample surface, and gamma rays were detected along the direction of proton incidence (behind the samples). Al amounts (areal densities) $Q_{\mathrm{Al}}$ were calculated from the area under excitation curves (not shown) after background subtraction and normalization for the number of incident protons, by using a standard $\mathrm{Al}_{2} \mathrm{O}_{3}$ film on $\mathrm{Si}$ as reference. The estimated precision is $\pm 10 \%$.

Aluminum profiling was accomplished by using the narrow $(\mathrm{FWHM}<40 \mathrm{eV}$ ) resonance at $404.9 \mathrm{keV}$ in the crosssection curve of the above-mentioned reaction. Proton incidence was at $60^{\circ}$ with respect to the normal to the sample surface, and gamma rays were again detected along the direction of proton incidence. Profiles were obtained from simulations of the experimental excitation curves by using the FLATUS program. The depth scale in the profiles was estimated by using (i) hafnium and aluminum areal densities, (ii) the calculated stopping power for protons in $\left(\mathrm{HfO}_{2}\right)_{x}\left(\mathrm{Al}_{2} \mathrm{O}_{3}\right)_{1-x}$ (in units of mass per area), and (iii) weighted averages of $\mathrm{Al}_{2} \mathrm{O}_{3}$ and $\mathrm{HfO}_{2}$ densities, respectively, 4.0 and $9.7 \mathrm{~g} / \mathrm{cm}^{3}$. Table I summarizes the elemental characterization data.

\section{RESULTS AND DISCUSSION}

In fitting the VUV-SE data with a single TL oscillator, we found that there was a large discrepancy between the mod- 

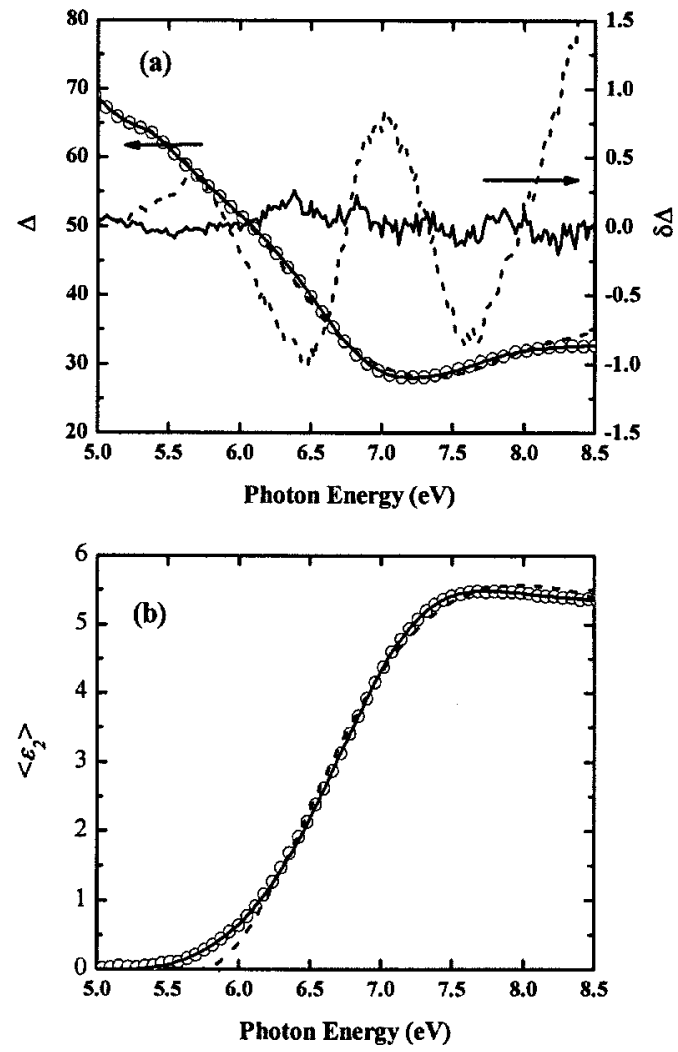

FIG. 2. (a) Comparisons between the experimental (open circles) and modeled (dashed line for the single TL and solid line for the double TLs) data $(\Delta)$ for sample S16. Fitting error $\delta \Delta$ depicts an excellent fit for the double TL model (solid line) compared with that of the single TL model (dashed line). (b) The corresponding inverted imaginary (open circles) part $\left\langle\varepsilon_{2}\right\rangle$ of the pseudodielectric function $\langle\varepsilon\rangle$ is compared with the single (dashed line) and double (solid line) TL dispersions. For reference, the fitting parameters obtained from (i) the single TL model: $\varepsilon_{\infty}=1.527, A=596.36 \mathrm{eV}, E_{g}$ $=5.77 \mathrm{eV}, E_{0}=6.13$, and $C=3.07 \mathrm{eV}$, and (ii) the double TL model: $\varepsilon_{\infty}$ $=1.234, A=154.21 \mathrm{eV}, E_{g}=5.30 \mathrm{eV}, E_{0}=7.04 \mathrm{eV}$, and $C=2.23 \mathrm{eV}$ (the first TL) and $A=225.53 \mathrm{eV}, E_{g}=6.85 \mathrm{eV}, E_{0}=8.44$, and $C=4.63 \mathrm{eV}$ (the second $\mathrm{TL})$.

eled and experimental data as displayed by the dashed curve in Fig. 2(a) for sample S16. Similar observations were made for all other samples (not shown). However, a sum of two TL oscillators improves the fit significantly, especially in the spectral range above $5.5 \mathrm{eV}$ as depicted by the almost zero fitting error $\delta \Delta$ (solid curve in Fig. 2). With the double TL model, the data fitting of all samples results in the film thicknesses listed in Table I. To verify that the double TL dispersion is in fact a correct one for the films, we employed a data inversion to obtain the complex pseudo dielectric functions $\langle\varepsilon\rangle$ directly. In this inversion technique, $\left\langle\varepsilon_{1}\right\rangle$ and $\left\langle\varepsilon_{2}\right\rangle$ of the films were calculated from the measured $\Psi$ and $\Delta$, oint by point at each photon energy by using the film thickness obtained from the fit with the TL dispersion. ${ }^{9}$ Figure 2(b) shows $\left\langle\varepsilon_{2}\right\rangle$ obtained by this inversion process (open circles) and from fitting the single (dashed curve) and double (solid curve) TL dispersions. The double TL dispersion is in excellent agreement with the calculated $\left\langle\varepsilon_{2}\right\rangle$, especially near the band gap, thus justifying the double TL dispersion model. Figure 3 depicts the representative (open circles) inversion
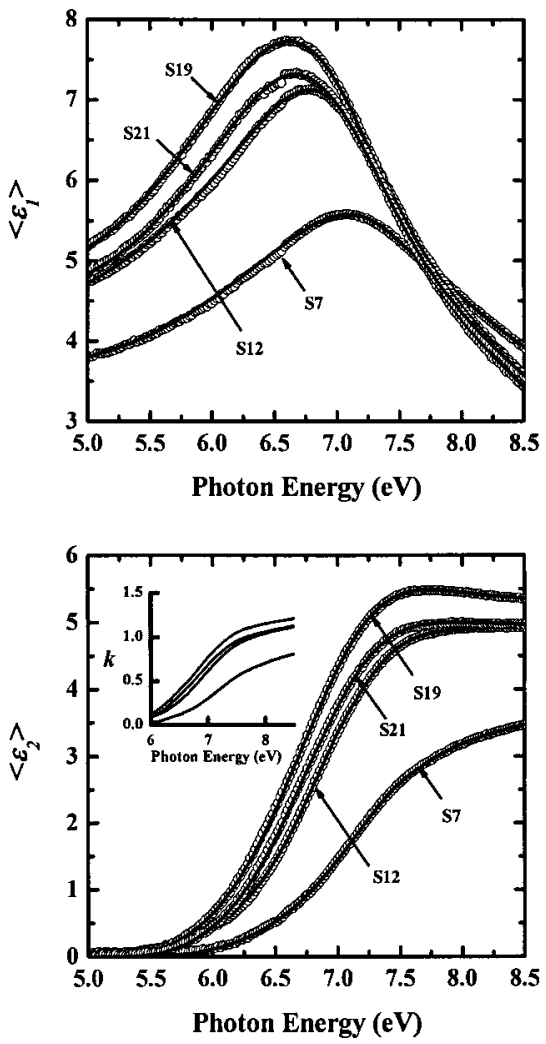

FIG. 3. Inverted dielectric functions (open circles), $\langle\varepsilon\rangle=\left\langle\varepsilon_{1}\right\rangle+\mathrm{i}\left\langle\varepsilon_{2}\right\rangle$ and the fitting double Tauc-Lorentz oscillator dispersion (solid curves) obtained for samples S7, S12, S19, and S21. The inset of the bottom graph depicts the distinction coefficient $k$ determined from $\left\langle\varepsilon_{1}\right\rangle$ and $\left\langle\varepsilon_{2}\right\rangle$.

$\langle\varepsilon\rangle$ spectrum compared with the modeled (solid curves) double TL dispersion obtained for samples $\mathrm{S} 7[1(\mathrm{HO})$ : 1(AO)], S12 [51(HO): 1(AO)], S19 [1(HO): 0(AO)], and $\mathrm{S} 21[37(\mathrm{HO}) / 5(\mathrm{AO}) / 37(\mathrm{HO})]$. The use of the double TL can be further justified by considering the energy band structure associated with transition metal/rare earth oxide modeled by Lukovsky et al. ${ }^{18,19}$ To be specific, it was argued that the optical fundamental band gap or the lowest energy optical transition observed in the optical spectrum results from the transition between the highest occupied valence band of non bonding oxygen atom $2 p-\pi$ states and the lowest Hafnium $d$-state conduction band. From the Tauc plot for samples $\mathrm{S} 16$ and $\mathrm{S} 19$, we obtained the band gap $E_{g}$ for $\mathrm{HfO}_{2}$ films, which are averaged to a value of $5.56 \mathrm{eV}$. This transition corresponds to the first TL oscillator. The second TL oscillator represents the second interband transition which is assumed to be associated with the (ionic band gap) transition between the highest occupied valence band of non bonding oxygen $2 p-\pi$ state and the Hf $s$ conduction band state.

One parameter of great interest is the optical band gap that we derive from the inverted dielectric functions. $E_{g}$ is sensitive to the composition and electronic structure of $\mathrm{HfO}_{2}$ and $\mathrm{Hf}$-aluminate films as discussed in the following sections. Even though $E_{g}$ 's were obtained from fitting the data to the TL model, they are not accurate due to the correlation between the fitting parameters, especially in the case of the double TL model. In fact, all $E_{g}$ 's obtained from the single 


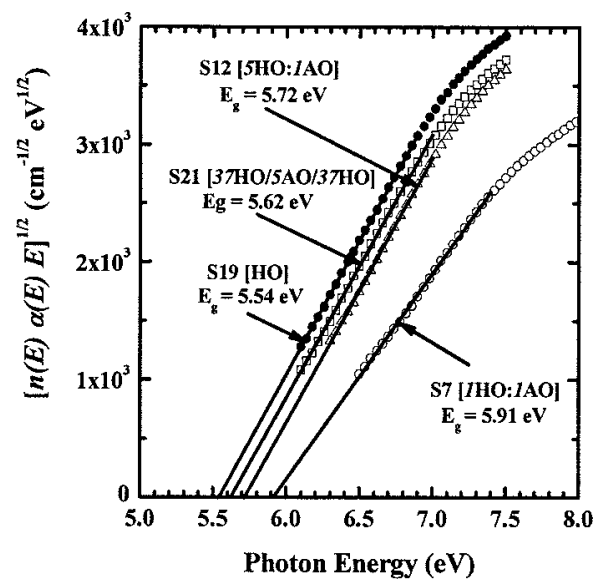

FIG. 4. Tauc plots for determining the optical band gap $E_{g}$ which is the intercept of the linear fitting curve extrapolated to the zero absorption for samples S7, S12, S19, and S21. The uncertainty on $E_{g}$ is $\pm 0.05 \mathrm{eV}$.

TL model are about $0.3 \mathrm{eV}$ below the real absorption edges (accurately determined in the following) whereas they vary widely in the double TL model. Generally, the band gap for an amorphous material is determined from the energy dependence of its absorption coefficient, $\alpha=4 \pi k / \lambda$, near its absorption edge, ${ }^{20}$ where $\lambda$ is the photon wavelength and $k$ is the extinction coefficient which can be calculated from $\varepsilon_{1}$ and $\varepsilon_{2}$ by the complex relation $(n+i k)^{2}=\left(\varepsilon_{1}+i \varepsilon_{2}\right)^{2}$ with $n$ being the index of refraction. The most commonly used method to acquire $E_{g}$ is to use the Tauc plot. ${ }^{21}$ Tauc and co-workers showed that near the absorption edge of some amorphous materials, the expression $[n(E) \alpha(E) E]^{1 / 2}$ varies linearly with $\left(E-E_{g}\right)$ where $E$ is the photon energy. If a straight line is obtained near the band edge in a plot of $[n(E) \alpha(E) E]^{1 / 2}$ versus the photon energy $E$, then the extrapolation to zero absorption results in the value of $E_{g}$. Figure 4 presents representative Tauc plots for samples S7, S12, S19, and S21. The portion of the spectrum between 6 and $7 \mathrm{eV}$ near the band edge clearly follows a linear relationship with the photon energy $E$ and was fitted to a straight line to obtain the bandgap values for all samples listed in Table I. The uncertainty of the $E_{g}$ was estimated to be approximately 0.05 $\mathrm{eV}$ for all samples. The uncertainty was deduced from the worst case as if there was no $\mathrm{SiO}_{2}$ interfacial layer used in the model or if the interface layer was not $\mathrm{SiO}_{2}$ but a hafnium silicate or an understoichiometric $\mathrm{SiO}_{x}$.

\section{A. Optical band gap $\mathrm{E}_{g}$ and dielectric function of $\mathrm{HfO}_{2}$}

There have been numerous reported values for $E_{g}$ of $\mathrm{HfO}_{2}$. Table II compiles a limited survey of reported $E_{g}$ of $\mathrm{HfO}_{2}$ grown by various techniques and determined mainly by optical measurements. From our data analyses, $E_{g}$ averaged on two $\mathrm{HfO}_{2}$ samples (S16 and S19) of two different thicknesses is $5.56 \mathrm{eV}$. Boher et al. ${ }^{13}$ employed both Grazing x-ray reflectance (GXR) and VUV-SE films and showed $E_{g}$ to be approximately $5.5 \mathrm{eV}$ from their $\mathrm{HfO}_{2}<\varepsilon>$ spectrum. In a much earlier study by Balog et al. ${ }^{22}$ the $E_{g}$ value of 5.65 $\mathrm{eV}$ of $\mathrm{HfO}_{2}$ film, fabricated by CVD, was obtained by the use of the same Tauc-plot method on absorbance data. Our own most recent studies on a set of jet-vapor-deposited $\mathrm{HfO}_{2}$ and Hf-aluminate films resulted in, however, a relatively lower $E_{g}$ value of $5.08 \mathrm{eV}$ for the $\mathrm{HfO}_{2}$ film. ${ }^{9}$ Lim et al. ${ }^{23}$ performed a transmission measurement on an $\mathrm{Y}_{2} \mathrm{O}_{3}$-stabilized single crystalline $\mathrm{HfO}_{2}$ and reported a higher $E_{g}$ value of $5.8 \mathrm{eV}$. All of the just listed $E_{g}$ 's were determined with the measured spectral range above the band gap. In another study performed on a large set of MOCVD $\mathrm{HfO}_{2}$ films by Modreanu et al. ${ }^{24}$ using only the data measured in a limited range of photon energy up to $4.5 \mathrm{eV}$, much below the band gap, they managed to deduce $E_{g}$ by using an empirical formula that relates the strength of the interband optical transitions. However, their $E_{g}$ were shown to vary in a wide range from 5.66 to $5.95 \mathrm{eV}$, possibly due to their samples experiencing various postgrowth annealing and the lack of experimental data above the band gap. For a comparison with a more elaborate physical technique such as the x-ray photoelectron spectroscopy (XPS) performed by $\mathrm{Yu}$ et al. ${ }^{25}$ on $\mathrm{ALD}\left(\mathrm{HfO}_{2}\right)_{x}\left(\mathrm{Al}_{2} \mathrm{O}_{3}\right)_{1-x}$, a lower $E_{g}$ value of 5.25 $\mathrm{eV}$ for $\mathrm{HfO}_{2}$ was calculated from the onset of the $\mathrm{O} 1 s$ band energy loss XPS spectra. In a recent internal electron photoemission study of ALD $\mathrm{HfO}_{2},{ }^{26} E_{g}$ was determined from the photoconductivity spectra and found to be $5.6 \mathrm{eV}$ in a good agreement with this report. Overall, $E_{g}$ varies in a range from $\approx 5$ to $\approx 6 \mathrm{eV}$ dependent on the techniques used to grow the films, as well as the particular optical characterization tool and the corresponding model used to determine $E_{g}$.

Another quantity that relates to the film structural quality is the relative magnitude of $\left\langle\varepsilon_{1}\right\rangle$ and $\left\langle\varepsilon_{2}\right\rangle$. In the following we compare $\left\langle\varepsilon_{1}\right\rangle$ and $\left\langle\varepsilon_{2}\right\rangle$ obtained for our $\mathrm{HfO}_{2}$ films with those published elsewhere. The $\mathrm{Y}_{2} \mathrm{O}_{3}$-stabilized $\mathrm{HfO}_{2}$ single

TABLE II. Brief survey of the $E_{g}$ reported in published literature.

\begin{tabular}{cccc}
\hline \hline Preparation method & $E_{g}\left(\mathrm{HfO}_{2}\right)(\mathrm{eV})$ & Optical techniques & References \\
\hline ALCVD & 5.56 & VUV-SE $(1.5-8.3 \mathrm{eV})$ & This article \\
ALCVD & $\approx 5.5^{\mathrm{a}}$ & VUV-SE & Boher et al. ${ }^{13}$ \\
CVD & 5.65 & Absorbance & Balog et al. ${ }^{22}$ \\
$\mathrm{HfO}_{2}$ single crystal & 5.8 & Transmission & Lim et al. ${ }^{11}$ \\
Jet-vapor deposition & 5.08 & VUV-SE $(1.5-8.3 \mathrm{eV})$ & Nguyen et al. ${ }^{9}$ \\
MOCVD & $5.66-5.95$ & SE $(1.5-4.5 \mathrm{eV})$ & Modreanu et al. ${ }^{24}$ \\
\hline
\end{tabular}

${ }^{\mathrm{a}}$ This value was not reported but estimated from $\left\langle\varepsilon_{2}\right\rangle$ spectrum. 


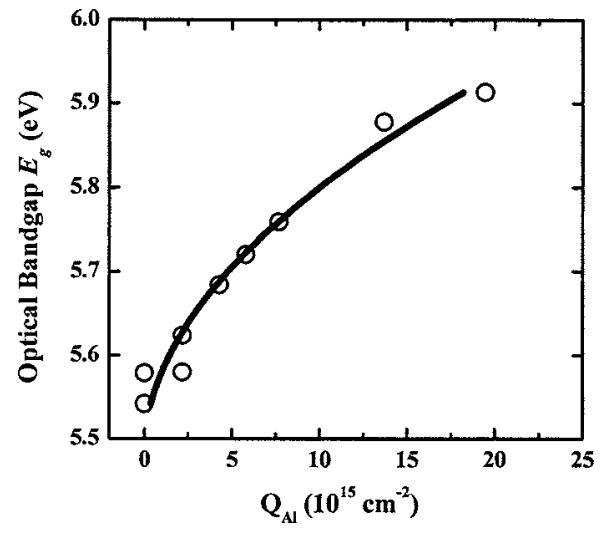

FIG. 5. Variation of $E_{g}$ determined by VUV-SE varies with respect to the aluminum (areal) density in the film obtained from NRA measurements. The solid line is a linear fit where the band gap $E_{g}$ of the endpoint of $\mathrm{Al}_{2} \mathrm{O}_{3}$ (not available in this study) was taken from our previous study (Ref. 9).

crystal of Lim et al. ${ }^{23}$ showed higher values of $\left\langle\varepsilon_{1}\right\rangle$ and $\left\langle\varepsilon_{2}\right\rangle$. Their peak values in $\varepsilon_{1}(\approx 10.5)$ and $\varepsilon_{2}(\approx 8.0)$ are much higher than our corresponding values of $\approx 7.8$ and $\approx 5.5$, respectively. These differences in $\langle\varepsilon\rangle$ and the corresponding larger band gap (see previous discussion) are due to the film being a single crystal as opposed to the amorphous films used in this study. The energy position of the main $\left\langle\varepsilon_{1}\right\rangle$ peak position at about $6.6 \mathrm{eV}$ observed for sample S19 (see Fig. 3) is similar to that of the single crystal of Lim et al. ${ }^{23}$ as well as of sputtered $\mathrm{HfO}_{2}$ (Ref. 27) and jet-vapor-deposited $\mathrm{HfO}_{2}{ }^{9}$. Boher et al. $^{13}$ showed the $k$ extinction coefficient peaked at $\approx 7.5 \mathrm{eV}$ but decreased at a higher photon energy range (from 7.5 up to $9.0 \mathrm{eV}$ ). Our $k$ (see the inset of Fig. 3) increases to a similar peak at $7.5 \mathrm{eV}$, but continues to increase above and beyond the experimental spectral range. It indicates there is another oscillator above $9.0 \mathrm{eV}$ which is qualitatively consistent with the existence of a high interband transition from the oxygen $2 p$ orbital to the Hf $s$ orbital. ${ }^{18}$ Further, a surface roughness layer determined from GXR data fitting was incorporated in the data analysis by Boher et al., ${ }^{13}$ indicating that the $\mathrm{HfO}_{2}$ film surface deposited by sputtering appears to be rough compared with the films prepared by ALCVD employed in this study. On the other hand, Sun et al. ${ }^{10}$ showed that the extinction coefficient $k$ of their ALD $\mathrm{HfO}_{2}$ also increases above the $\approx 7.5 \mathrm{eV}$ peak in a good agreement with our $\mathrm{HfO}_{2}$ results. This agreement implies that $\mathrm{HfO}_{2}$ films grown by ALD are optically comparable, and their corresponding electronic structures are in agreement with the electronic orbital model of transitional metals. ${ }^{18}$ It is desired that high- $\kappa$ materials remain amorphous throughout the device fabrication process to avoid high-leakage current. $^{28}$ The dielectric functions, especially in the imaginary part $\left\langle\varepsilon_{2}\right\rangle$, have been reported to exhibit an additional and relatively sharp peak $(\approx 5.9 \mathrm{eV})$ above the fundamental band gap when the films became polycrystalline under hightemperature annealing. ${ }^{29}$ Our own most recent studies on jetvapor-deposited polycrystalline $\mathrm{Hf}$-aluminate films also displayed a shoulder peak at $\sim 5.7 \mathrm{eV}$ just above the band gap and below the main broader peak at $\approx 7.0 \mathrm{eV}$. ${ }^{9}$ Based on the

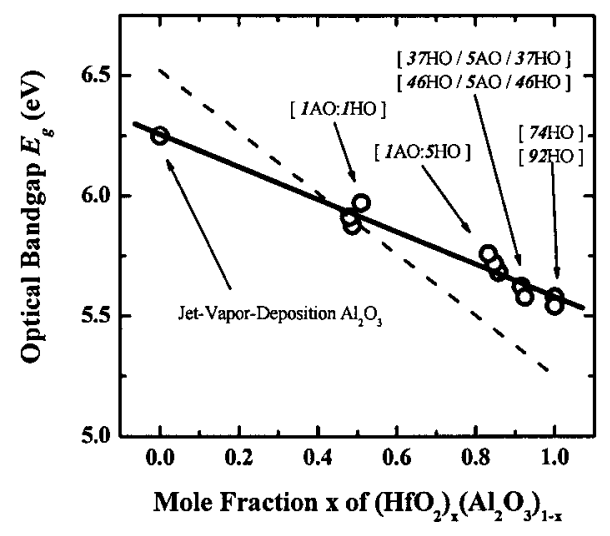

FIG. 6. Plot of $E_{g}$ versus the mole fraction $x$ of the $\left(\mathrm{HfO}_{2}\right)_{x}\left(\mathrm{Al}_{2} \mathrm{O}_{3}\right)_{1-x}$ alloyed films. The solid line $\left(E_{g}=6.26-0.68 x\right)$ is the linear least squares fitting of $E_{g}$. The dashed curve is the linear relation $\left(E_{g}=6.52-1.27 x\right)$ reported by $\mathrm{Yu}$ et al. ${ }^{25}$

results of these previous reports on the polycrystalline $\mathrm{HfO}_{2}$ films, our low temperature grown ALCVD films remain amorphous as evidenced by the absence of the $5.7 \mathrm{eV}$ polycrystalline feature. The amorphous nature of these films is also clearly supported by the HRTEM images shown in Fig. 1. A similar conclusion was reached for ALD $\mathrm{HfO}_{2} / \mathrm{Al}_{2} \mathrm{O}_{3}$ film stacks whereby cross-sectional HRTEM pictures of asdeposited $\mathrm{HfO}_{2}$ on a nontreated reaction barrier $\mathrm{Al}_{2} \mathrm{O}_{3}$ layer had a completely amorphous structure. ${ }^{30}$

\section{B. Optical band gap $E_{g}$ and dielectric function of $\left(\mathrm{HfO}_{2}\right)_{x}\left(\mathrm{Al}_{2} \mathrm{O}_{3}\right)_{1-x}$ alloy films}

The effects of alloying with $\mathrm{Al}_{2} \mathrm{O}_{3}$ in the growth of $\left(\mathrm{HfO}_{2}\right)_{x}\left(\mathrm{Al}_{2} \mathrm{O}_{3}\right)_{1-x}$ films on the optical band gap $E_{g}$ and the pseudo dielectric functions are depicted in Figs. 5 and 6. A parabolic dependency of $E_{g}$ on the $\mathrm{Al}$ density is clearly shown in Fig. 5, where the absolute areal densities Al were measured by NRA (see Table. I). On the other hand, in terms of relative $\mathrm{Hf}$ and $\mathrm{Al}$ composition, as seen in Fig. 6, the $E_{g}$ varies linearly with the mole fraction $x$ of $\mathrm{HfO}_{2}$ in the $\left(\mathrm{HfO}_{2}\right)_{x}\left(\mathrm{Al}_{2} \mathrm{O}_{3}\right)_{1-x}$ alloys, where $x$ was calculated from the ratio of the $\mathrm{Hf} / \mathrm{Al}$ areal densities measured by both RBS and NRA described previously. The fact that the band gap $E_{g}$ increases with the higher $\mathrm{Al}_{2} \mathrm{O}_{3}$ mole fraction implies that a chemical intermixing of $\mathrm{HfO}_{2}$ and $\mathrm{Al}_{2} \mathrm{O}_{3}$ occurred in the ALD processes. It is believed that the intermixing of these two transition metal oxides, with $\mathrm{Al}_{2} \mathrm{O}_{3}$ having a larger band gap, increases the separation of the oxygen $2 p$ orbital valence band state and the antibonding $d$ states intermixed of $\mathrm{Hf}$ and $\mathrm{Al}$, and therefore results in a larger band gap. ${ }^{18}$ Note that the endpoint $\left(\mathrm{Al}_{2} \mathrm{O}_{3}\right.$ or $\left.x=0, E_{g}=6.25 \mathrm{eV}\right)$ was not available in this study and was taken from our previous similar studies of HfAlO films grown by the jet-vapor deposition. ${ }^{9}$ $E_{g}$ of thin $\mathrm{Al}_{2} \mathrm{O}_{3}$ film has been observed to be smaller than that of bulk $\mathrm{Al}_{2} \mathrm{O}_{3}$ crystal, ${ }^{26}$ indicating that the deposited oxides are structurally and electronically different from the bulk crystal of the same oxide. By using least squares fitting, we obtained $E_{g}=6.26-0.68 x(\mathrm{eV})$ shown by the solid line in Fig. 6. In the study by Yu et al. ${ }^{25}$ mentioned previously, XPS 


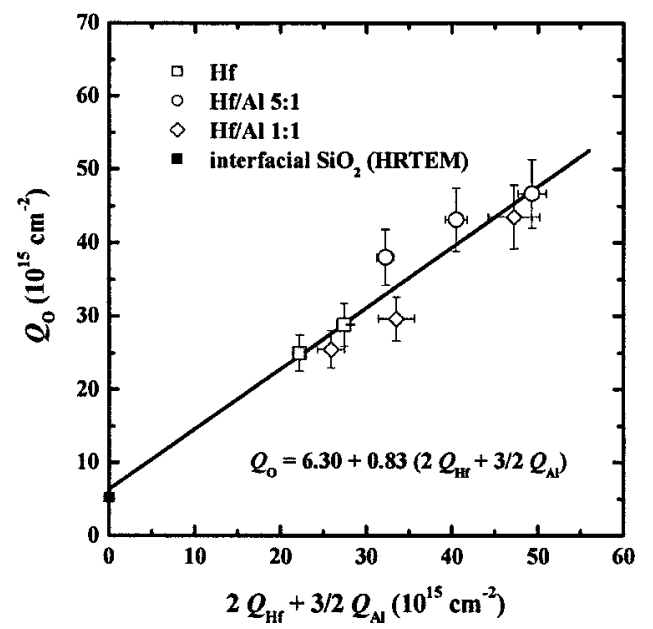

FIG. 7. Plot of $Q_{\mathrm{O}}$ versus $\left(2 Q_{\mathrm{Hf}}+2 / 3 Q_{\mathrm{Al}}\right)$ where $Q_{\mathrm{O} \text { and Hf }}$ are the elemental amounts (areal densities) calculated from the area of the channeling RBS signals and $Q_{\mathrm{Al}}$ profile determined by resonant NRA. Ideal $\left(\mathrm{HfO}_{2}\right)_{x}\left(\mathrm{Al}_{2} \mathrm{O}_{3}\right)_{1-x}$ alloy films on $\mathrm{Si}$ yields a straight line of unit slope crossing the origin. A linear fit indicates a positive intercept at the $y$ axis consistent with $\approx 12 \AA$ of interfacial $\mathrm{SiO}_{2}$.

data also show a linear relation, $E_{g}=6.52-1.27 x(\mathrm{eV})$, depicted by the dashed line. Both studies agree in terms of the linear dependency of increasing band gap with increasing $\mathrm{Al}$ mole fraction. It is noted that, by extrapolating $x$ to 0 , we obtained the $E_{g}$ value of $6.26 \mathrm{eV}$ for the jet-vapor-deposited amorphous $\mathrm{Al}_{2} \mathrm{O}_{3}$ film, which is lower than that of $6.52 \mathrm{eV}$ measured by XPS. However, the XPS data show that $E_{g}$ started at a much lower value of $5.25 \mathrm{eV}$ for the $\mathrm{HfO}_{2}$ compared with the averaged $E_{g}(\sim 5.56 \mathrm{eV})$ from samples $\mathrm{S} 16$ and S19 and increased at a higher rate. The origins of this discrepancy possibly stem from (i) the material quality and preparation methods used in each study, and (ii) the methodology of how $E_{g}$ was deduced. The XPS-derived $E_{g}$ relies on the onset of energy loss from energy-loss spectra of the core electron oxygen $1 s$ energy-loss spectra, whereas $E_{g}$, deduced from the optical method, is commonly based on the optical energy absorption near the band gap. The latter method has been well established for amorphous materials (which were used in this study) which follow the Tauc-law formula described and used previously. Further, from Fig. 3, since overall the magnitude of $\left\langle\varepsilon_{1}\right\rangle$ and $\left\langle\varepsilon_{2}\right\rangle$ decreases and the Lorentz (second $E_{0}$ in the TL dispersion) oscillator peak position shifts to higher energy with increasing $\mathrm{Al}$ content, $\mathrm{HfO}_{2}$ and $\mathrm{Al}_{2} \mathrm{O}_{3}$ are believed to be intermixed in the alloy.

Figure 7 presents the plot of oxygen atomic concentration $\left(Q_{\mathrm{O}}\right)$ versus $\left(2 Q_{\mathrm{Hf}}+\frac{2}{3} Q_{\mathrm{Al}}\right)$. Ideal $\left(\mathrm{HfO}_{2}\right)_{x}\left(\mathrm{Al}_{2} \mathrm{O}_{3}\right)_{1-x}$ alloy films on Si should yield a straight line of unit slope crossing the origin. A linear fit to our data indicates a positive intercept at the $y$ axis consistent with an interfacial $\mathrm{SiO}_{2}$ thickness of $\approx 12 \AA$, in very good agreement with HRTEM results (Fig. 1). The slope, 0.8, indicates that the films could be slightly oxygen deficient with respect to the prototypical ideal alloys. Al profiles are consistent with uniform distribu- tion of $\mathrm{Al}$ in the films (within the resolution of NRA), with the exception of sample S24, in which an Al-containing layer is stacked between two Hf-containing layers.

At this juncture, it is important to point out the discrepancies that could arise from the inclusion of the $\mathrm{SiO}_{2}$ interfacial layer in the SE model when comparing with the results otherwise obtained from the single-layer (without the interfacial layer) model. As described previously about the modeling of the $\mathrm{SE}$ data, the thickness of $\mathrm{SiO}_{2}$ interface (from HRTEM) was used as a fixed value in the data analysis that determined the $\mathrm{HfO}_{2}$ and $\mathrm{Hf}$-aluminate layer thicknesses and their dielectric functions. However, with the single-layer model, we found that the resulting thicknesses for all samples were approximately 3\% less than the sum of the thickness of the fixed $\mathrm{SiO}_{2}$ interface and the film obtained from the two-layer model. In addition, the single-layer $E_{g}$ 's are approximately $0.05 \mathrm{eV}$ larger than those deduced from the model with the fixed $\mathrm{SiO}_{2}$ interfacial layer. However, the relative magnitudes in $\varepsilon_{1}$ and $\varepsilon_{2}$ and the value of $E_{g}$ vary consistently with the relative amount of $\mathrm{Al}$ in the films in either model. It is also noticed that the film thicknesses of $\mathrm{HfO}_{2}$ of sample S5 and HfAlO of sample S7 determined from the two-layer model are approximately $0.4 \mathrm{~nm}$ thicker than those obtained from the corresponding HRTEM. These differences could come from the different beam sizes employed in the SE and HRTEM. SE results are averaged over a much larger $(\approx 2 \mathrm{~mm} \times 4 \mathrm{~mm})$ area of the sample whereas HRTEM focuses on a much smaller area of $\approx 0.5 \mu \mathrm{m}$ $\times 2 \mu \mathrm{m}$ cross section. In addition, the boundary of the film at the interfaces may not be uniquely defined in the HRTEM images.

\section{SUMMARY}

VUV-SE has been used to investigate the optical properties of a set of $\mathrm{HfO}_{2}$ and $\mathrm{Hf}$-aluminate films fabricated by ALCVD with various $\mathrm{Al}_{2} \mathrm{O}_{3}$ compositions. The modeling and data analyses were presented and shown to reproduce the experimental data very well. The various growth sequences, by changing the ratio of $\mathrm{HfO}_{2}$ and $\mathrm{Al}_{2} \mathrm{O}_{3}$ precursors, produced different aluminum densities in the HfAlO films. RBS and resonant NRA measurements were performed to obtain the hafnium, oxygen, and aluminum concentrations and profiles. The determined complex pseudo dielectric functions $(\langle\varepsilon\rangle)$ by VUV-SE for all the $\mathrm{HfO}_{2}$ and $\mathrm{HfAlO}$ films exhibit the shift of the fundamental band gap $E_{g}$ from $\approx 5.56 \mathrm{eV}$ of $\mathrm{HfO}_{2}$ to $\approx 5.92 \mathrm{eV}$ of HfAlO grown by a $(1: 1)$ ratio of $\mathrm{HfO}_{2}$ and $\mathrm{Al}_{2} \mathrm{O}_{3}$ precursors. Also it was consistently observed that the magnitude of $\left\langle\varepsilon_{1}\right\rangle$ and $\left\langle\varepsilon_{2}\right\rangle$ decreased with increasing $\mathrm{Al}$ content in the films. In terms of the mole fraction of $\mathrm{Al}_{2} \mathrm{O}_{3}$ in the alloy $\left(\mathrm{HfO}_{2}\right)_{x}\left(\mathrm{Al}_{2} \mathrm{O}_{3}\right)_{1-x}$, a linear relation, $E_{g}=6.26$ $-0.68 x$, was experimentally observed. However, $E_{g}$ follows a parabolic function with respect to the areal density of aluminum. HRTEM images taken on the same samples revealed amorphous structure of as-grown ALCVD films, clearly confirming the amorphous characteristics observed in the dielectric functions determined by SE. 
This study has demonstrated the powerful, nondestructive, and relatively economical capabilities of VUV-SE that can be used for in situ and online monitoring and/or controlling of the depositions of technically relevant high- $k$ dielectric gates in advanced IC devices. Particularly, in addition to thickness measurements traditionally and routinely performed by ellipsometry in IC device fabrication, the band gap and the optical properties can be determined and then used as growth monitoring parameters to assess and control compositions as well as structural qualities of high- $k$ films.

\section{DISCLAIMER}

Certain commercial equipment, instruments, or materials are identified in this paper in order to specify the experimental procedure adequately. Such identification is not intended to imply recommendation or endorsement by the National Institute of Standards and Technology, nor is it intended to imply that the materials or equipment identified are necessarily the best available for the purpose.

\section{ACKNOWLEGMENTS}

Three of the authors (N.V.N., J.R.E., and S.S.) express their appreciation and gratitude for the continuous financial support from the NIST Office of Microelectronics Programs (OMP). Another author (P.Y.H.) would like to thank Jeff Peterson for his discussion on the ALCVD process.

${ }^{1}$ R. M. Wallace and G. Wilk, MRS Bull. 27, 212 (2002).

${ }^{2}$ Semiconductor Industry Association, The International Technology Roadmap for Semiconductors, 2001 Ed., (International SEMATECH, Austin, TX, 2001)

${ }^{3}$ C. A. Richter, A. R. Hefner, and E. M. Vogel, IEEE Electron Device Lett. 22, 35 (2001)

${ }^{4}$ G. D. Wilk, R. M. Wallace, and J. M. Anthony, J. Appl. Phys. 89, 5243 (2001).

${ }^{5}$ D. G. Schlom and J. H. Haeni, MRS Bull. 27, 198 (2002).

${ }^{6}$ W. J. Zhu, T. Tamagawa, M. Gibson, T. Furukawa, and T. P. Ma, IEEE Electron Device Lett. 23, 649 (2002).

${ }^{7}$ M.-Y. Ho, H. Gong, G. D. Wilk, W. W. Busch, M. L. Green, W. H. Lin, A. See, S. K. Lahiri, M. E. Loomans, Petri I. Räisänen, and T. Gustafsson, Appl. Phys. Lett. 81, 4218 (2002).

${ }^{8}$ H. Y. Yu, N. Wu, M. F. Li, C. Zhu, B. J. Cho, D.-L Kwong, C. H. Tung, J. S. Pan, J. W. Chi, W. D. wang, D. Z. Chi, C. H. Ang, J. Z. Zeng, and S. Ramantan, Appl. Phys. Lett. 81, 3618 (2002).

${ }^{9}$ N. V. Nguyen, J.-P. Han, J. Y. Kim, E. Wilcox, Y. J. Cho, W. Zhu, Z. Luo, and T. P. Ma, Characterization and Metrology for ULSI Technology,
International Conference, edited by D. G. Seiler, A. C. Diebold, T. J. Shaffner, R. McDonald, S. Zollner, R. P. Khosla, and E. M. Secula (AIP Press, Melville, NY, 2003), pp. 181-185.

${ }^{10}$ L. Sun, C. Defranoux. J. L. Stehle, P. Boher, P. Evrard, E. Bellandi, and H. Bender, Mater. Res. Soc. Symp. Proc. 786, E3.29.1 (2004).

${ }^{11}$ S.-G. Lim, S. Kriventsov, T. N. Jackson, J. H. Haeni, G. G. Schlom, A. M. Balbashov, R. Uecker, P. Reiche, J. L. Freeouf, and G. Lucovsky, J. Appl. Phys. 91, 4500 (2002).

${ }^{12}$ J. N. Hilfiker, C. L. Bungay, R. A. Synowicki, T. E. Tiwald, C. M. Herzinger, B. Johs, G. K. Pribil, and J. A. Woollam, J. Vac. Sci. Technol. A 21, 1103 (2003).

${ }^{13}$ P. Boher, P. Evrard, J. P. Piel, C. Defranoux, J. C. Fouere, E. Bellandi, and H. Bender, Characterization and Metrology for ULSI Technology, International Conference, edited by D. G. Seiler, A. C. Dielbold, T. J. Shaffner, R. McDonald, S. Zollner, R. P. Khosla, and E. M. Secula (AIP Press, Melville, NY, 2003), pp. 148-153.

${ }^{14}$ W. F. A. Besling, E. Young, T. Conard, C. Zhao, R. Carter, W. Vandervorst, M. Caymax, S. De. Gendt, M. Heyns, J. Maes, M. Tuominen, and S. Haukka, J. Non-Cryst. Solids 303, 123 (2002).

${ }^{15}$ M. Copel, M. Gribelyuk, and E. Gusev, Appl. Phys. Lett. 76, 436 (2000).

${ }^{16}$ B. Johs, J. A. Woollam, C. M. Herzinger, J. Hilfiker, R. Synowicki, and C. L. Bundgay, Proc. SPIE CR72, 29 (1999).

${ }^{17}$ G. E. Jellison, Jr. and F. A. Modine, Appl. Phys. Lett. 69, 371 (1996); 69, 2137 (1996).

${ }^{18}$ G. Lukovsky, J. L. Whitten, and Y. Zhang, Microelectron. Eng. 59, 329 (2001).

${ }^{19}$ G. Lucovsky, J. L. Whitten, and Y. Zhang, Solid-State Electron. 46, 1687 (2002).

${ }^{20}$ A. S. Ferlauto, G. M. Ferreira, J. M. Pearce, C. R. Wrongski, R. W. Collins, X. Deng, and G. Ganguly, J. Appl. Phys. 92, 2424 (2002).

${ }^{21}$ J. Tauc, R. Grigorovici, and A. Vancu, Phys. Status Solidi 15, 627 (1966).

${ }^{22}$ M. Balog, M. Schieber, M. Michman, and S. Patai, Thin Solid Films 41, 247 (1977).

${ }^{23}$ S.-G. Lim, S. Kriventsov, T. N. Jackson, J. H. Haeni, D. G. Schlom, A. M. Balbashov, J. L. Freeouf, and G. Lucovsky, J. Appl. Phys. 91, 4500 (2002).

${ }^{24}$ M. Modreanu, P. K. Hurley, B. J. O’Sullivan, B. O'Looney, J. P. Senateur, H. Rousell, F. Rousell, M. Audier, C. Dubourdieu, I. W. Boyd, Q. Fang, T. L. Leedham, S. Rushworth, A. C. Jones, H. Davies, and C. Jimenez, Proc. SPIE 4876, 1236 (2002).

${ }^{25}$ H. Y. Yu, F. Li, B. J. Cho, C. C. Yeo, M. S. Joo, D.-L. Kwong, J. S. Pan, C. H. Ang, J. Z. Zheng, and S. Ramanathan, Appl. Phys. Lett. 81, 376 (2002).

${ }^{26}$ V. V. Afanas'ev and A. Stesmans, Appl. Phys. Lett. 82, 245 (2003).

${ }^{27}$ P. Boher, P. Evrard, J. P. Piel, J. L. Stehle, J. Non-Cryst. Solids 303, 167 (2002).

${ }^{28}$ W. J. Zhu, T. Tamagawa, G. Gibson, T. Furukawa, and T. P. Ma, IEEE Electron Device Lett. 23, 649 (2002).

${ }^{29}$ Y. J. Cho, N. V. Nguyen, C. A. Richter, J. R. Ehrstein, B. H. Lee, and J. C. Lee, Appl. Phys. Lett. 80, 1249 (2001).

${ }^{30}$ H. B. Park, M. Cho, J. Park, S. W. Lee, C. S. Hwang, and J. Jeong, Electrochem. Solid-State Lett. 7, F25 (2004). 